Pacific Journal of Mathematics

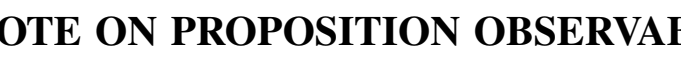




\title{
A NOTE ON PROPOSITION OBSERVABLES
}

\author{
Stanley P. Gudder
}

We consider some questions which were brought up in a previous paper: (1) If the product of two proposition observables is a proposition observable, do the corresponding propositions split? (2) What is the relationship, if any, between the concepts of compatibility and simultaneity of proposition observables? It is shown that the answer to (1) is yes and as a corollary we find the partial answer to (2) that compatibility implies simultaneity. It is also proved that the sum of two proposition observables is a proposition observable if and only if the corresponding propositions are orthogonal and also that $\left(x_{a} \circ x_{b}\right)^{n}$ converges weakly to $x_{a \wedge b}$ as $n \rightarrow \infty$.

We assume that all observables are defined on a quite full logic satisfying conditions $U$ and $E$. (See [1] for definitions and notation.) Recall that an observable $x$ is a proposition observable if $\sigma(x) \subset\{0,1\}$. (These observables are also called questions, cf. [3].) If $x(\{1\})=a$ we denote $x$ by $x_{a}$. It is clear that proposition observables behave, in some respects, like orthogonal (self-adjoint) projections on a Hilbert space and for this reason it is natural to consider certain properties of projections and ask whether these properties are retained by proposition observables. For example, it is easy to show that if $A$ and $B$ are orthogonal projections then $A+B$ is an orthogonal projection if and only if $A B=B A=0$ and $A B$ is an orthogonal projection if and only if $A B=B A$ ([4], Th. 13.4). Also if $C$ is the orthogonal projection on the range of $A$ intersected with the range of $B$ then $C$ is the strong operator limit of the sequence $A, B A, A B A, B A B A, \cdots$ ([4] Th. 13.7). We show that these results generalize to proposition observables. Recall that the product $x \circ y$ of two bounded observables $x, y$ is $x \circ y=\frac{1}{2}\left[(x+y)^{2}-x^{2}-y^{2}\right]$ and that $x$ and $y$ are compatible if $x \circ(z \circ y)=(x \circ z) \circ y=(x \circ y) \circ z$ for all bounded observables $z$.

\section{The theorems.}

LEMMA 1. The following statements are equivalent. (i) $a \leftrightarrow b$. (ii) $m(a)=1, m(a \wedge b)=0$ implies $m(b)=0$ for any state $m$. (iii) $\sigma\left(x_{a}+x_{b}\right) \subset\{0,1,2\}$.

Proof. Since $a=(a-a \wedge b)+(a \wedge b)$ and $b=(b-a \wedge b)+(a \wedge b)$, $a \leftrightarrow b$ if and only if $(a-a \wedge b) \perp(b-a \wedge b)$. But the latter holds if and only if $m(a-a \wedge b)=1$ implies $m(b-a \wedge b)=0$. This last condition is equivalent to (ii) and hence (i) and (ii) are equivalent. 
Since $\sigma\left(x_{a}+x_{b}\right) \subset[0,2]$ applying Lemma $6.2[1]$ we have

$$
\begin{aligned}
m(a) & +m(b)=m\left(x_{a}+x_{b}\right)=\int_{[0,2]} \lambda m\left[\left(x_{a}+x_{b}\right)(d \lambda)\right] \\
& \left.=m\left[x_{a}+x_{b}\right)(\{1\})\right]+m(a \wedge b)+m\left[\left(x_{a}+x_{b}\right)\left(\{0,1,2\}^{\prime}\right)\right] .
\end{aligned}
$$

If $\sigma\left(x_{a}+x_{b}\right) \subset\{0,1,2\}$ and $m(a)=1, m(a \wedge b)=0$ then

$$
m(b)=m\left[\left(x_{a}+x_{b}\right)(\{1\})\right]-1=0,
$$

and hence $a \leftrightarrow b$. Conversely if $a \leftrightarrow b$ it easily follows that

$$
m\left[\left(x_{a}+x_{b}\right)(\{1\})\right]=m\left(a \wedge b^{\prime}\right)+m\left(b \wedge a^{\prime}\right)
$$

for every state. It then follows that $\left(x_{a}+x_{b}\right)\left(\{0,1,2\}^{\prime}\right)=0$ and hence $\sigma\left(x_{a}+x_{b}\right) \subset\{0,1,2\}$.

THEOREM 2. The following statements are equivalent. (i) $x_{a} \circ x_{b}$ is a proposition observable. (ii) $x_{a} \circ x_{b}=x_{a \wedge b}$. (iii) $a \leftrightarrow b$.

Proof. It follows from Lemma $6.6[1]$ that (iii) $\Rightarrow$ (ii) $\Rightarrow$ (i). To show (i) $\Rightarrow$ (iii) suppose $x_{a} \circ x_{b}$ is a proposition observable. Define the continuous function $f(\lambda)=\frac{1}{2}\left(\lambda^{2}-\lambda\right)$. Since a proposition observable is its own square we have

$$
\{0,1\} \supset \sigma\left(x_{a} \circ x_{b}\right)=\sigma\left[\frac{1}{2}\left(\left(x_{a}+x_{b}\right)^{2}-\left(x_{a}+x_{b}\right)\right)\right]=\sigma\left[f\left(x_{a}+x_{b}\right)\right] .
$$

Applying the spectral mapping theorem (Theorem 4.2 [2]) we have $f\left(\sigma\left(x_{a}+x_{b}\right)\right) \subset\{0,1\}$. We then conclude that $\sigma\left(x_{a}+x_{b}\right) \subset\{0,1,2\}$ and using Lemma 1 we have that $a \leftrightarrow b$.

Corollary 3. If $x_{a}$ and $x_{b}$ are compatible, then $x_{a} \leftrightarrow x_{b}$.

Proof. If $x_{a}$ and $x_{b}$ are compatible, then

$$
\left(x_{a} \circ x_{b}\right)^{2}=\left(x_{a} \circ x_{b}\right) \circ\left(x_{a} \circ x_{b}\right)=\left(\left(x_{a} \circ x_{b}\right) \circ x_{a}\right) \circ x_{b}=\left(x_{a} \circ x_{b}\right) \circ x_{b}=x_{a} \circ x_{b}
$$

and hence $x_{a} \circ x_{b}$ is a proposition observable. Applying Theorem 2, $a \leftrightarrow b$ and hence $x_{a} \leftrightarrow x_{b}$.

COROLLARY 4. The following statements are equivalent. (i) $x_{a}+x_{b}$ is a proposition observable. (ii) $a \perp b$. (iii) $\sigma\left(x_{a}+x_{b}\right) \subset[0,1]$. (iv) $x_{a} \circ x_{b}=0$.

Proof. From Theorem 2 and Theorem 6.7 [1] we deduce that (iv) $\Leftrightarrow$ (ii) $\Rightarrow$ (i) and it is trivial that (i) $\Rightarrow$ (iii). Now (iii) is equivalent to $0 \leqq m(a)+m(b) \leqq 1$ or $m(a) \leqq 1-m(b)$ for every state $m$. But 
this last statement is equivalent to (ii) and thus (iii) and (ii) are equivalent.

CoRollary 5. The following statements are equivalent. (i) $x_{b}-x_{a}$ is a proposition observable. (ii) $a \leqq b$. (iii) $\sigma\left(x_{b}-x_{a}\right) \subset[0,1]$. (iv) $x_{a} \circ x_{b}=x_{a}$.

Proof. Replace $b$ by $b^{\prime}$ in Corollary 4.

We say that a sequence of observables $x_{n}$ converges weakly to an observable $x$ if $\lim _{n \rightarrow \infty} m\left(x_{n}\right)=m(x)$ for every state $m$.

THEOREM 6. The sequence of observables $\left(x_{a} \circ x_{b}\right)^{n}$ converges weakly to the proposition observable $x_{a \wedge b}$.

Proof. Let $z=x_{a} \circ x_{b}$ and again let $f(\lambda)=\frac{1}{2}\left(\lambda^{2}-\lambda\right)$. Then using the spectral mapping theorem and the fact that $\sigma\left(x_{a}+x_{b}\right) \subset[0,2]$ we have

$$
\sigma(z)=\sigma\left(f\left(x_{a}+x_{b}\right)\right)=f\left(\sigma\left(x_{a}+x_{b}\right)\right) \subset f([0,2]) \subset[-1 / 8,1] .
$$

Since

$$
m\left(z^{n}\right)=\int_{[-1 / 8,1)} \lambda^{n} m[z(d \lambda)]+m[z(\{1\})]
$$

we have

$$
\left|m\left(z^{n}\right)-m[z(\{1\})]\right| \leqq \int_{[-1 / 8,1)}|\lambda|^{n} m[z(d \lambda)] .
$$

Applying the dominated convergence theorem, the integral approaches zero as $n \rightarrow \infty$ and hence $\lim _{n \rightarrow \infty} m\left(z^{n}\right)=m[z(\{1\})]$. Applying Lemma $6.2[1]$ we have

$$
\begin{aligned}
z(\{1\}) & =f\left(x_{a}+x_{b}\right)(\{1\})=\left(x_{a}+x_{b}\right)\left[f^{-1}(\{1\})\right] \\
& =\left(x_{a}+x_{b}\right)(\{-1,2\})=\left(x_{a}+x_{b}\right)(\{2\})=a \wedge b
\end{aligned}
$$

and since $m\left(x_{a \wedge b}\right)=m(a \wedge b)$, the proof is complete.

CoRollary 7. The sequence of observables $\left.I-\left[I-x_{a}\right) \circ\left(I-x_{b}\right)\right]^{n}$ converges weakly to the proposition observable $x_{a \vee b}$.

REMARKs. Strictly speaking Theorem 6 is not exactly a generalization of Von Neumann's Theorem 13.7 [4], however it is probably the most natural form that a corresponding result would take under these more general circumstances. Notice that our definition of compatibility is stronger than that given in [1]. 


\section{REFERENCES}

1. S.P. Gudder, Uniqueness and existence properties of bounded observables, Pacific J. Math. 19 (1966), 81-93.

2. Spectral methods for a generalized probability theory, Trans. Amer. Math. Soc. 119 (1965), 428-442.

3. G. W. Mackey, The mathematical foundations of Quantum mechanics, W. A. Benjamin Inc., New York, 1963.

4. J. von Neumann, Functional operators, Vol. II, Princeton University Press, 1950.

Received August 9, 1967. While conducting research for this paper the author was supported by NSF contract GP-6764. 


\section{PACIFIC JOURNAL OF MATHEMATICS}

\section{EDITORS}

H. ROYDEN

Stanford University

Stanford, California

R. R Phelps

University of Washington

Seattle, Washington 98105
J. DUGUNDJI

Department of Mathematics

University of Southern California

Los Angeles, California 90007

RICHARD ARENS

University of California

Los Angeles, California 90024

\section{ASSOCIATE EDITORS}
E. F. BECKENBACH
B. H. NeumanN
F. WOLF
K. YosidA

\section{SUPPORTING INSTITUTIONS}

UNIVERSITY OF BRITISH COLUMBIA

CALIFORNIA INSTITUTE OF TECHNOLOGY

UNIVERSITY OF CALIFORNIA

MONTANA STATE UNIVERSITY

UNIVERSITY OF NEVADA

NEW MEXICO STATE UNIVERSITY

OREGON STATE UNIVERSITY

UNIVERSITY OF OREGON

OSAKA UNIVERSITY

UNIVERSITY OF SOUTHERN CALIFORNIA
STANFORD UNIVERSITY

UNIVERSITY OF TOKYO

UNIVERSITY OF UTAH

WASHINGTON STATE UNIVERSITY

UNIVERSITY OF WASHINGTON

AMERICAN MATHEMATICAL SOCIETY CHEVRON RESEARCH CORPORATION TRW SYSTEMS

NAVAL WEAPONS CENTER 


\section{Pacific Journal of Mathematics

Vol. 28, No. $1 \quad$ March, 1969

Patrick Robert Ahern, On the geometry of the unit ball in the space of real annihilating measures .............................. 1

Kirby Alan Baker, Equational classes of modular lattices ............. 9

E. F. Beckenbach and Gerald Andrew Hutchison, Meromorphic minimal surfaces ......................................... 17

Tae Ho Choe, Intrinsic topologies in a topological lattice ..............

John Bligh Conway, A theorem on sequential convergence of measures and

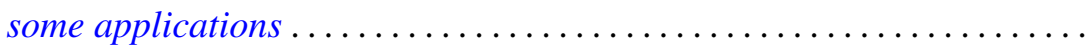

Roger Cuppens, On the decomposition of infinitely divisible probability laws without normal factor.

Lynn Harry Erbe, Nonoscillatory solutions of second order nonlinear

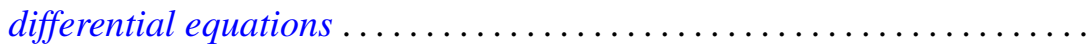

Burton I. Fein, The Schur index for projective representations of finite

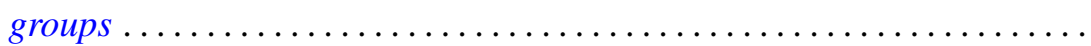

Stanley P. Gudder, A note on proposition observables............... 101

Kenneth Kapp, On Croisot's theory of decompositions ............... 105

Robert P. Kaufman, Gap series and an example to Malliavin's theorem . . . 117

E. J. McShane, Robert Breckenridge Warfield, Jr. and V. M. Warfield,

Invariant extensions of linear functionals, with applications to measures and stochastic processes ................

Marvin Victor Mielke, Rearrangement of spherical modifications ...

Akio Osada, On unicity of capacity functions ..............

Donald Steven Passman, Some 5/2 transitive permutation groups ...

Harold L. Peterson, Jr., Regular and irregular measures on groups and dyadic spaces...

Habib Salehi, On interpolation of $q$-variate stationary stochastic processes...

Michael Samuel Skaff, Vector valued Orlicz spaces generalized

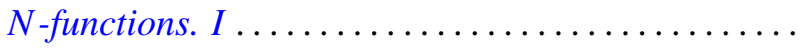

A. J. Ward, On $H$-equivalence of uniformities. II...........

Thomas Paul Whaley, Algebras satisfying the descending chain condition for subalgebras...

G. K. White, On subgroups of fixed index

Martin Michael Zuckerman, A unifying condition for implications among the axioms of choice for finite sets ................. 